\title{
Protective effect of nobiletin against apoptosis induced by 6 -hydroxydoamine in human neuroblastoma cells
}

\author{
Roksana SoukhakLari ${ }^{1,2}$, Majid Reza Farokhi ${ }^{1}$, Maryam Moosavi ${ }^{3 *}$ \\ 1. Shiraz Neuroscience Research Center, Shiraz University of Medical Sciences, Shiraz, Iran \\ 2. Students Research Committee, School of Medicine, Shiraz University of Medical Sciences, Shiraz, Iran \\ 3. Nanobiology and Nanomedicine Research Centre, Shiraz University of Medical sciences, Shiraz, Iran
}

\begin{abstract}
Introduction: Parkinson's disease (PD) is the second most common neurodegenerative disorder characterized by the damage of dopaminergic neurons of substantia nigra. Despite considerable research, therapeutic approaches aimed at the prevention and long-term treatment of PD have not been quite successful. Therefore, there is a tendency for the identification of novel medical intervention derived from natural substances. Nobiletin, an important citrus flavonoid commonly present in sweet and bitter orange peel, has been suggested to act as a neuroprotective agent in animal models of PD. This study was aimed to assess the potentials of nobiletin in preventing neuronal death and caspase-3 in SH-SY5Y cells.
\end{abstract}

Methods: SH-SY5Y cells were grown in DMEM/F12 media supplemented with 10\% fetal bovine serum. The 6-hydroxydopamine (6-OHDA) with or without nobiletin was added to cells. After $24 \mathrm{~h}$, the cells were examined for morphological changes under a light microscope and viability by MTT assay. The protective doses of nobiletin was chosen through a pilot study and accordingly the doses 50 and $250 \mu \mathrm{M}$ were selected for further assessments. Western blot assays were done to examine the effect of 6 OHDA with/without nobiletin on cleaved (active) caspase-3.

Results: Our results showed that nobiletin is effective in attenuating the effect of 6 OHDA on cell viability by the MTT assay. Nobiletin also reduced the cleavage of caspase-3 induced by 6-OHDA.

Conclusion: These results suggest that nobiletin has protective effects against dopaminergic neural toxicity and its anti-apoptotic effect is involved, at least in part, in such protection.

http://dx.doi.org/10.32598/ppj.24.1.20

\section{Keywords: \\ Nobiletin; \\ SH-SY5Y; \\ Caspase-3; \\ Cell viability; \\ 6-OHDA}

\author{
* Corresponding author: \\ Maryam Moosavi \\ Email: \\ marmoosavi@sums.ac.ir \\ Tel: +98 (71) 36281517 \\ Received 10 June 2019; \\ Received in revised form 1 \\ September 2019; Accepted 5 \\ October 2019
}

\section{Introduction}

Nobiletin is a polymethoxylated flavone present in citrus fruits (Sasaki and Yoshizaki, 2002). Nobiletin is reported to exert some favorable effects, like anti- oxidative, anti-inflammatory and immunomodulatory (Huang et al., 2016). Several lines of evidence have also shown its neuroprotective effects in animal models of Alzheimer's disease (AD) (Onozuka et al., 2008) and Parkinson's disease (PD) (Yabuki et al., 
2014; Jeong et al., 2015; Braidy et al., 2017).

$\mathrm{PD}$, the second most prevalent neurodegenerative disease (Lees et al., 2009), is characterized with dopaminergic neuronal loss in substantia nigra and intracytoplasmic substances named Lewy bodies (Forno, 1996). Levodopa is a well-known treatment of $\mathrm{PD}$, but its long term use leads to the side effects including farther oxidative stress (Dorszewska et al., 2014).

Apoptosis has been suggested as a plausible mechanism in PD pathogenesis (Khan et al., 2015). Considerable in vitro studies both in non-neuronal and neuronal cells demonstrated caspases are the effectors of apoptosis (Cohen, 1997). In neurons, increasing evidence indicated that caspase-3 plays an important role in the executive stage of apoptosis (Chaudhry and Ahmed, 2013). Activated caspase-3 has been shown in the substantia nigra of $P D$ patients and therefore caspase- 3 has been implicated in the pathogenesis of PD (Hartmann et al., 2000). In animal and cellular models of PD, the neurotoxins frequently used to induce experimental $P D$, such as 6-hydroxydopamine (6-OHDA) and 1-methyl-4phenylpyridinium $\left(\mathrm{MPP}^{+}\right)$have been reported to activate caspase-3 to exert their pro-apoptotic effects (Dodel et al., 1999; Lotharius et al., 1999). However, gene disruption of caspase-3 has been reported to prevent

1-methyl-4-phenyl-1,2,3,6tetrahydropyridine- (MPTP)-induced PD in mice (Yamada et al., 2010).

The SH-SY5Y neuroblastoma cell line is widely used to generate a cellular model of PD (Xie et al., 2010) since they share many functional and biochemical properties with mature dopaminergic neural cells. The 6-OHDA, as an analog of dopamine, has a hydroxyl group which specifically damages dopaminergic neurons making that toxic for dopaminergic neural cells (Ferger et al., 2001). Exposure to 6-OHDA leads to apoptosis in dopaminergic cells of substantia nigra (He et al., 2000) and SH-SY5Y cell line (Ikeda et al., 2008; Amiri et al., 2016). In the present study we aimed to examine the protective effect of nobiletin against 6-OHDA toxicity in human SH-SY5Y cell line.

\section{Materials and methods}

\section{Materials}

Human neuroblastoma cell line (SH-SY5Y) was purchased from Pasteur institute of Iran. Cell culture materials including Dulbecco's modified Eagle medium (DMEM/F12, 32500-035), fetal bovine serum (FBS, 10270-106), L-glutamine (10270106) and penicillin-streptomycin (15140-122), were purchased from Gibco life technologies. Nobiletin (N1538), 6OHDA (H4381) and MTT (3-[4,5-dimethylthiazol-2-yl]2,5-diphenyl tetrazolium bromide, M5655) were purchased from Sigma-Aldrich. Western blot antibodies including caspase-3 antibody (9665), betaactin antibody (4970) and secondary HRP-conjugated antibody (7074) were purchased from Cell Signaling Technology. Amersham ECL select (RPN2235) reagent kit was purchased from GE health care. Bovine serum albumin (BSA, 1120180100) and polyvinylidene difluoride (PVDF) membrane (IPVH00010) was purchased from Millipore. Other reagents were obtained from usual commercial sources.

\section{Cell culture}

SH-SY5Y cells were cultured in DMEM/ F12 supplemented with $10 \%$ heat-inactivated FBS, $2 \mathrm{mM}$ L-glutamine, $50 \mathrm{U} / \mathrm{ml}$ penicillin and $50 \mu \mathrm{g} / \mathrm{ml}$ streptomycin. The cells were maintained in a humidified atmosphere of $95 \%$ air and $5 \% \mathrm{CO}_{2}$ at $37^{\circ} \mathrm{C}$. The cells were used in the exponential growth phase and below passage 10 in all experiments. For cell viability studies, the cells were plated in 96 well and for western blotting studies, 6-well plates were used.

\section{Cell treatment}

The 6-OHDA, dissolved in sterile distilled water which contained $0.1 \%$ ascorbic acid as a stock solution $(6 \mathrm{mM})$, was added to cell culture medium to achieve the required concentration (50 $\mu \mathrm{M}$ (Amiri et al., 2016; Moosavi et al., 2018; Sookhaklari et al., 2019). Nobiletin was stored at $-20^{\circ} \mathrm{C}$ as a stock solution of $100 \mathrm{mM}$ in dimethyl sulfoxide (DMSO). The 6-OHDA and nobiletin were diluted in cell culture media immediately before use. To acquire the protective doses of nobiletin, a pilot test was done and the doses 1, 5, 10, 20, 50, 75, 100, 150, 200 and 250 $\mathrm{M}$ (Cui et al., 2010; Nemoto et al., 2013) were assessed. According to the results of this preliminary study, nobiletin at doses 50 and $250 \mu \mathrm{M}$ (chosen as the minimum and the maximum protective doses) was used for the following experiments.

Six cell groups were prepared and the control group was exposed to vehicles of the drugs. Cells in the 6- 


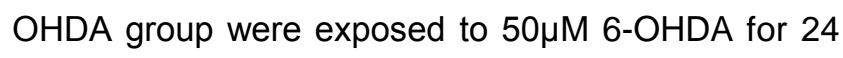
hours. Cells in the 6-OHDA+nobiletin group were

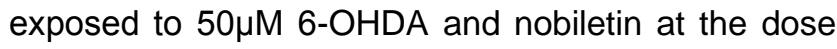
of 50 or $250 \mu \mathrm{M}$ for 24 hours. Cells in the nobiletin groups were treated with nobiletin at dose 50 or $250 \mu \mathrm{M}$ for 24 hours to assess any possible interaction effects.

\section{Assessment of cell viability and morphological changes}

Cell viability was detected using colorimetric MTT assay. SH-SY5Y cells were seeded in 96-well plates at a density of $1 \times 10^{4}$ cells/well and grown for $24 \mathrm{~h}$. Afterwards, the cells were incubated with 6-OHDA and/or nobiletin for 24 hours. The cells incubated in culture media containing an equivalent concentration of DMSO (less than $0.1 \%$ ) were considered as the control cells. Thereafter, the cells were incubated in fresh MTT solution/cell culture media (final concentration $0.5 \mathrm{mg} / \mathrm{ml}$ ) for $4 \mathrm{~h}$ at $37^{\circ} \mathrm{C}$. Then, the

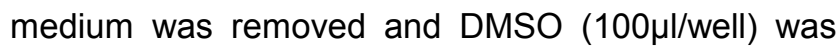
added to dissolve the formazan crystals. Following $15 \mathrm{~min}$ of homogenization, the cell viability was determined by absorbance of samples at $570 \mathrm{~nm}$ using a microplate reader (Synergy HT, Biotek ${ }^{\circledR}$ ). Morphological changes were observed under a light microscope (Nikon, ECLIPSE Ts2).

\section{Western blot assays}

SH-SY5Y cells were washed with phosphate-buffered saline and lysed with ice-cold RIPA (Radioimmunoprecipitation assay) buffer containing $50 \mathrm{mM}$ Tris- $\mathrm{HCl} \mathrm{pH}=8.0,150 \mathrm{mM} \mathrm{NaCl}, 1 \%$ Triton X$100,0.5 \% \mathrm{Na}$-Deoxycholate and $0.1 \%$ SDS (sodium dodecyl sulfate) supplemented with protease and phosphatase inhibitor cocktail. Following incubation for $30 \mathrm{~min}$ at $4^{\circ} \mathrm{C}$, the samples were centrifuged at $13,000 \mathrm{rpm}$ for $30 \mathrm{~min}$. The protein levels were determined using Lowry method (Lowry et al., 1951). Briefly, equal amounts of protein were separated by electrophoresis in $10 \%$ SDS polyacrylamide gels and transferred onto PVDF membranes. The membranes were incubated with $5 \%$ bovine serum albumin in Tris-buffered saline containing $0.1 \%$ Tween 20 (TBST) for $1 \mathrm{~h}$ to block nonspecific binding. Afterwards, the membranes were incubated overnight at $4^{\circ} \mathrm{C}$ with primary antibodies against caspase-3 $(1 / 3000)$ and $\beta$-actin (1/4000). After washing with TBST, the membranes were incubated for 1 hour at room temperature with secondary horseradish peroxidase-conjugated antibodies (anti-rabbit IgG, 1/10000). The membranes were washed again with TBST and the immunolabeling developed using ECL select kit. The protein levels were quantified by densitometry using Image $\mathrm{J}$ software.

\section{Statistical analysis}

The data are expressed as the mean \pm SEM of 3 independent experiments. One-way analysis of variance (ANOVA) followed by Tukey's post hoc test was performed for multiple group comparisons using GraphPad Prism software, version 6. A value of $P<0.05$ was considered statistically significant.

\section{Results}

\section{The effects of 6-OHDA and/or nobiletin on the viability of SH-SY5Y cells}

According to MTT assay results, 6-OHDA decreased the viability of SH-SY5Y cells (Fig. 1). In order to obtain the protective doses of nobiletin, a pilot study was done and the doses 1, 5, 10, 20, 50, 75, 100, 150, 200 and $250 \mu \mathrm{M}$ were exposed to cells. The analysis by one-way ANOVA revealed a significant difference $(F(11,24)=5.205, P=0.0004)$. Tukey's post hoc test indicated that nobiletin exert a protective effect at doses $\geq 50 \mu \mathrm{M}$ (Fig. 1). Therefore, the doses 50 and $250 \mu \mathrm{M}$ were selected for further assessment. Figure 2 compares cell viability when nobiletin at dose 50 or $250 \mu \mathrm{M}$ was added. One-way ANOVA indicated a difference between groups $(F(5,12)=$ 8.346, $P=0.0013)$. Tukey's post hoc test revealed that when nobiletin was added to 6-OHDA treated cells, it attenuated the effect of 6-OHDA on cell viability while nobiletin $(50$ or $250 \mu \mathrm{M})$ alone did not affect cell viability comparing to control group (Fig. 2).

\section{The effects of 6-OHDA and/or nobiletin on morphology of SH-SY5Y cells}

As depicted in Figure 3, following 6-OHDA treatment, cell shrinkage occurs, the cell loses its particular neuronal shape and its size decreased. Treatment with nobiletine at doses 50 and $250 \mu \mathrm{M}$ attenuates these changes.

\section{Nobiletin reversed 6-OHDA- induced caspase-3 cleavage}

To assess the level of cleaved caspase- 3 western blot technique was used. Cleaved caspase-3 
Fig. 1

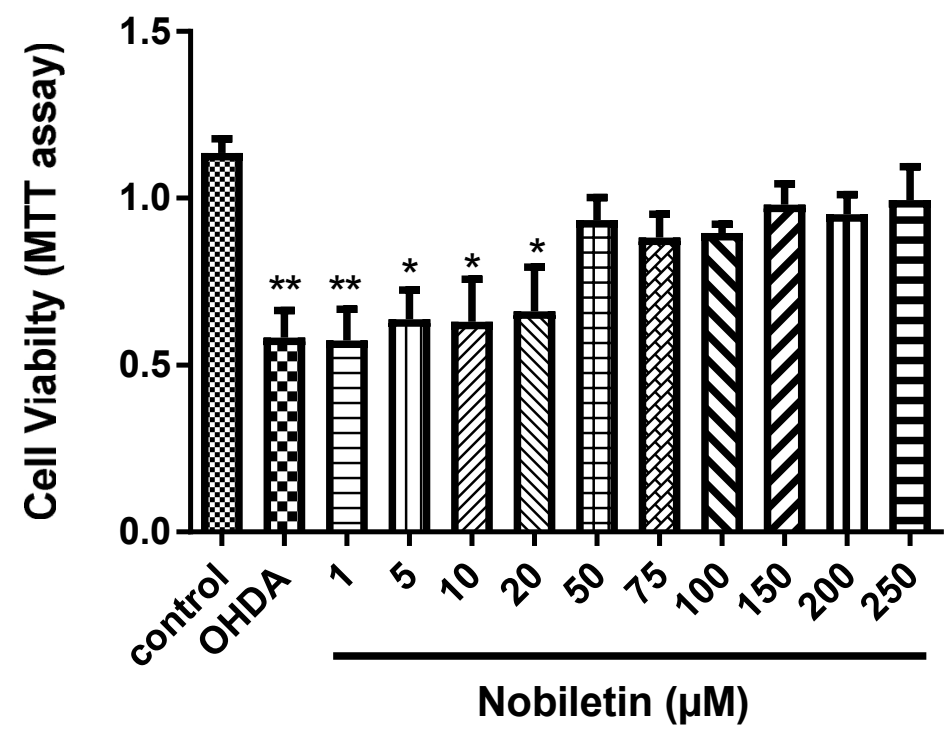

Fig.1. Effect of nobiletin at doses $1,5,10,20,50,75,100,150,200$ and $250 \mu \mathrm{M}$ on cell viability changes of 6OHDA treated SH-SY5Y cells. Cell viability was assessed through MTT assay and data are shown as mean \pm SEM of three independent experiments. ${ }^{*} P<0.05$ and ${ }^{* *} P<0.01$ show the difference versus control cells.

Fig. 2

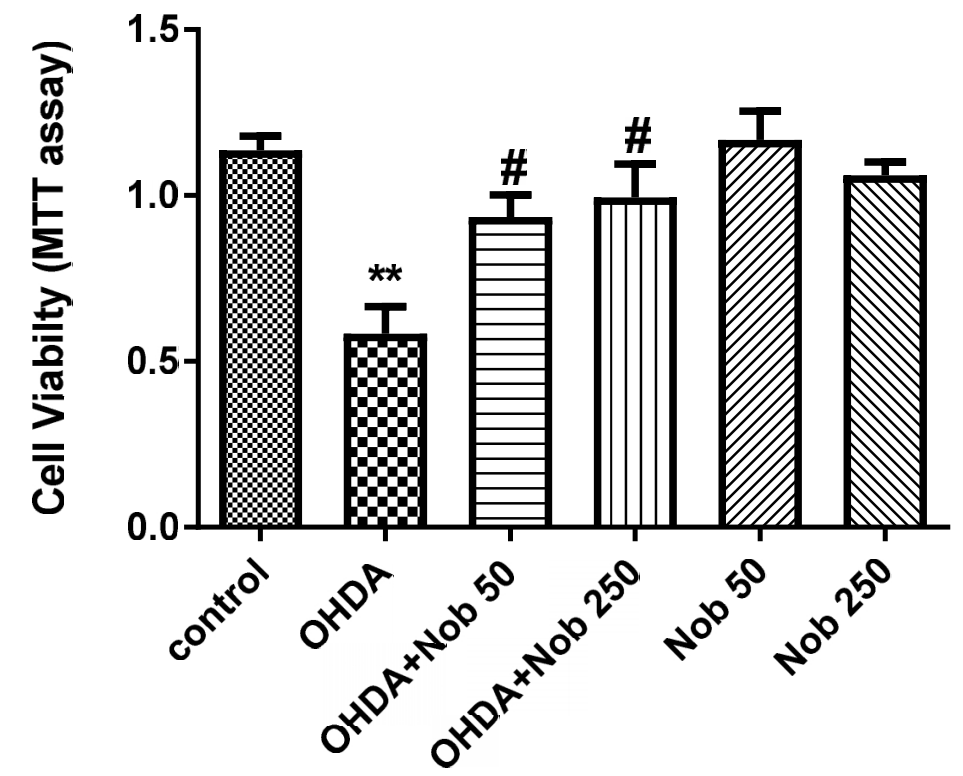

Fig.2. Effect of selected doses of nobiletin (50 and $250 \mu \mathrm{M})$ on 6-OHDA-treated SH-SY5Y cells. Cell viability was determined via MTT assay and data shown are mean \pm SEM of three independent experiments. ${ }^{* *} P<0.01$ represents the difference versus control cells while ${ }^{\#} P<0.05$ shows the difference versus $6-O H D A$ treated cells and nobiletin co-treated ones. 
Control

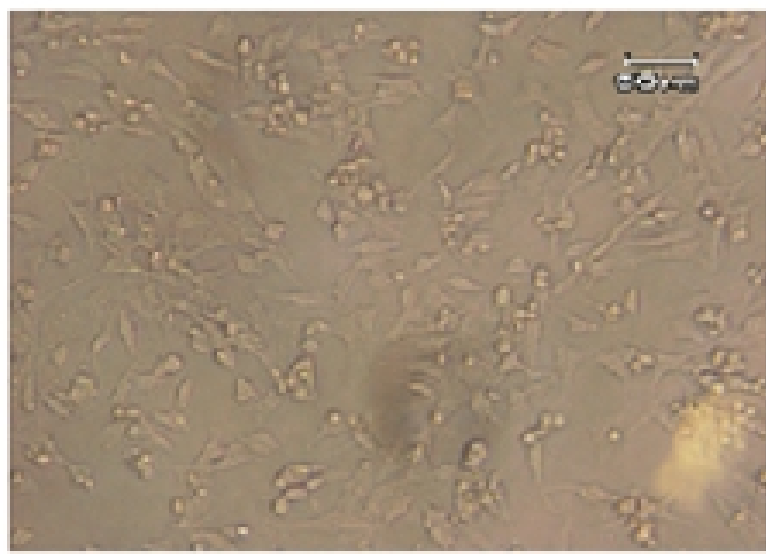

OHDA+Nobiletin $50 \mu \mathrm{M}$

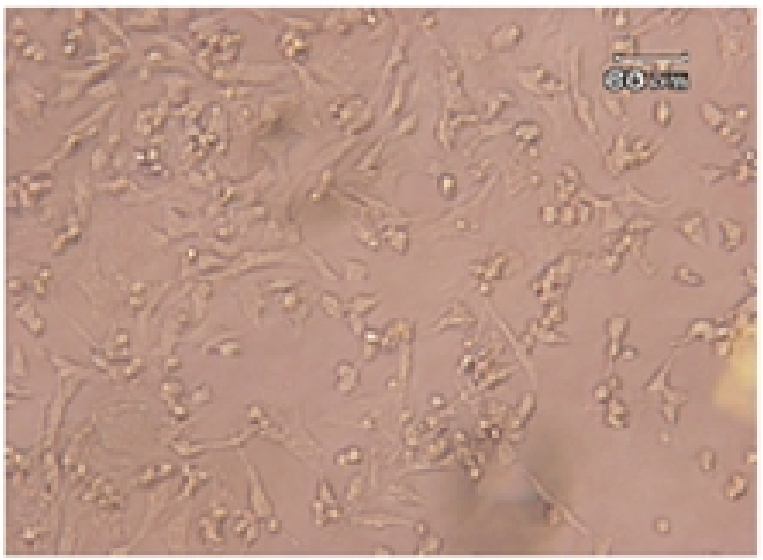

Nobiletin $50 \mu \mathrm{M}$

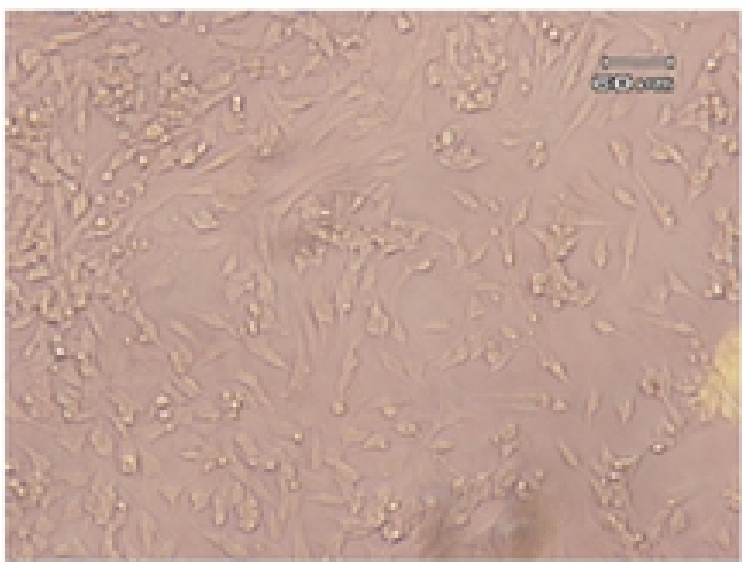

OHDA

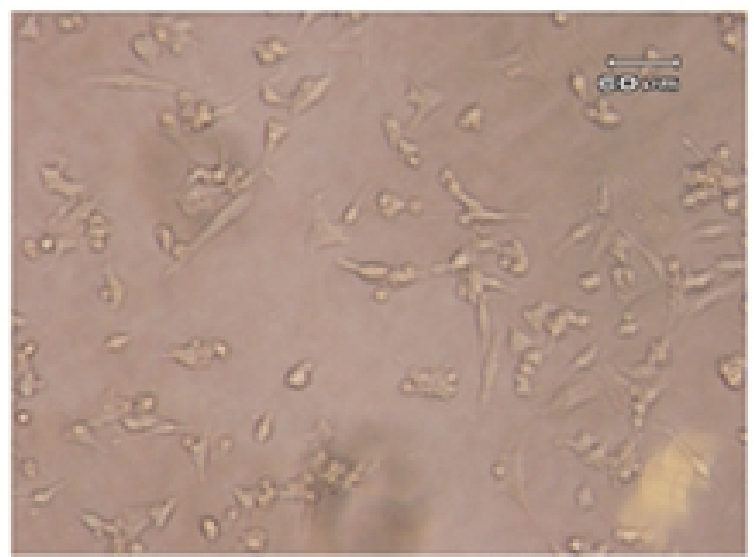

OHDA+Nobiletin $250 \mu \mathrm{M}$

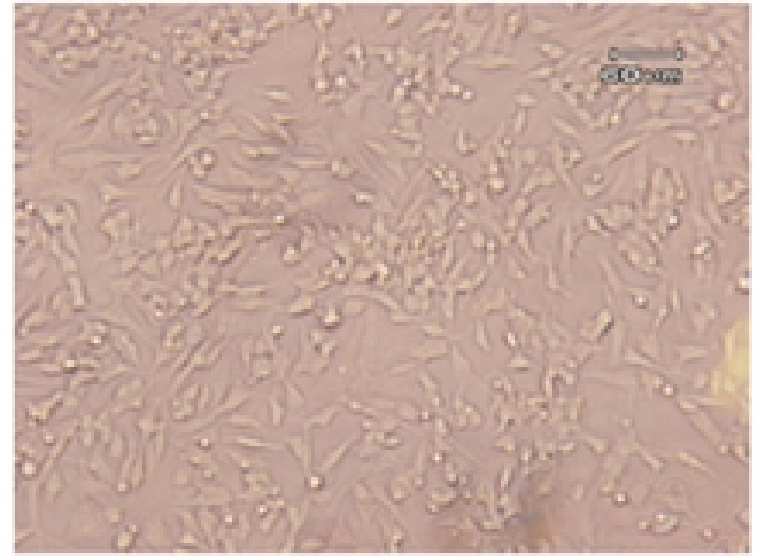

Nobiletin $250 \mu \mathrm{M}$

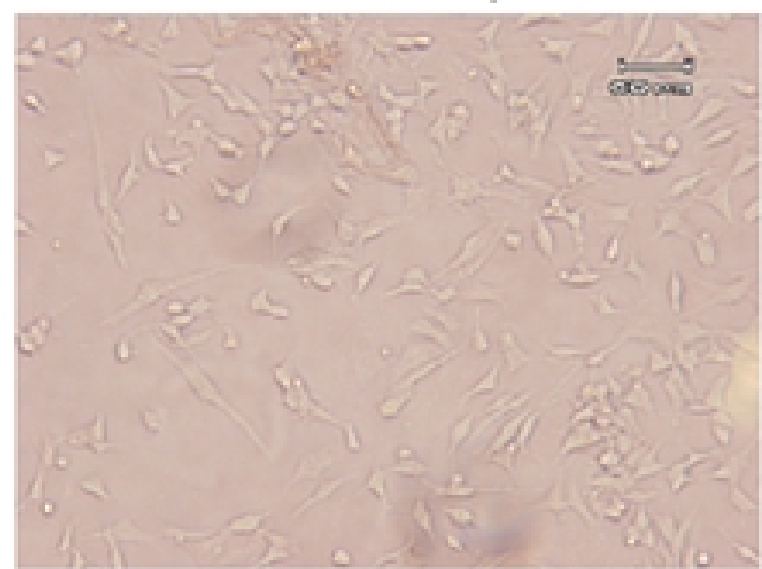

Fig.3. Effect of nobiletin at doses 50 and $250 \mu \mathrm{M}$ on morphological changes induced by 6 -OHDA. Microscopic images were taken $24 \mathrm{~h}$ after treatment. Following 6-OHDA treatment, cell shrinkage occurs, the cell loses its particular neuronal shape and its size decreased. Treatment with nobiletine at doses 50 and $250 \mu \mathrm{M}$ attenuates these changes.

appeared as a band at $19 \mathrm{kDa}$ (Fig. 2A). One-way ANOVA revealed a significant difference between groups $(F(3,8)=18.03, P=0.0006)$. Tukey's post hoc test, indicated that 6-OHDA exposure leads to a significant increase in caspase-3 cleavage $(P<0.001)$, while nobiletin co-treatment reduced the level of cleaved caspase-3 at doses $50(P<0.05)$ and $250 \mu \mathrm{M}$ $(P<0.01)$.

\section{Discussion}

Since there is a lack of efficient therapies for PD, the approach of neuroprotection attributing to the 
Fig. 4

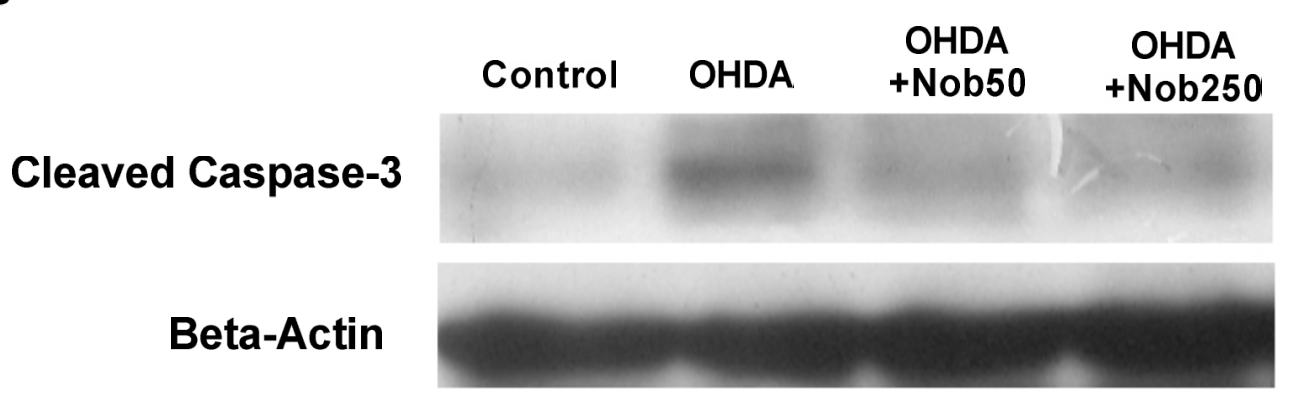

19 kD

$45 \mathrm{kD}$

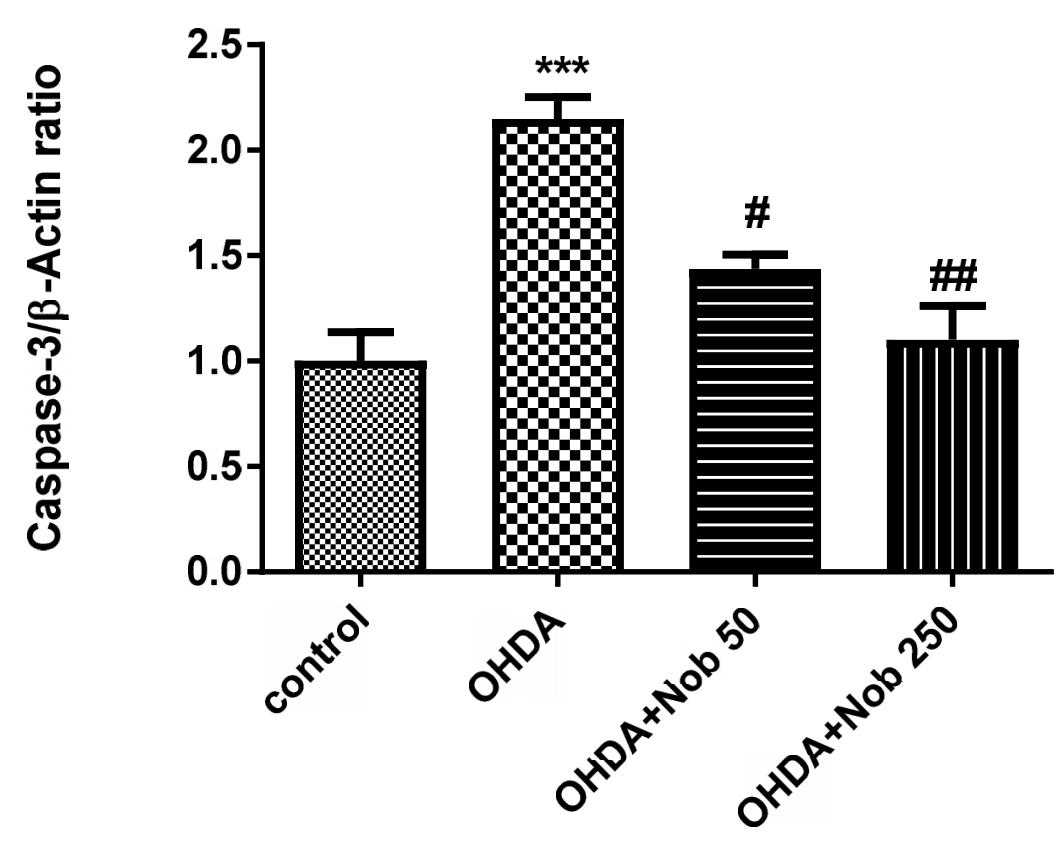

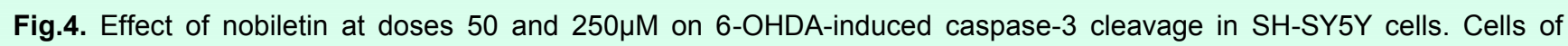
different groups were analyzed by western blot technique to determine the level of cleaved caspase-3. The graph represents the densitometry results which are shown as mean \pm SEM of three independent experiments. ${ }^{* * *} P<0.001$ shows the difference versus control cells while ${ }^{\#} P<0.05$ and ${ }^{\# \#} P<0.01$ indicate the difference versus $6-O H D A$ treated cells.

prevention of dopaminergic cell death, seems to be a hopeful concept. In this field, natural polyphenols such as nobiletin have been much considered during recent decade (Braidy et al., 2017). In the present study, the human neuroblastoma cell line exposed to 6-OHDA was used as an in vitro model of PD. The results indicated that: 1) the incubation of cells with 6-OHDA for $24 \mathrm{~h}$ decreased cell viability by about $50 \%$. Using the MTT assay, it was also revealed that nobiletin co-treatment decreased the cell loss induced by $6-\mathrm{OHDA}$ exposure; 2) there was a significant increase in the level of cleaved caspase3 in 6-OHDA treated neuroblastoma cells while cotreatment with nobiletin at doses 50 and $250 \mu \mathrm{M}$ reversed the increase in the cleaved caspase- 3 level. The selective loss of dopaminergic neural cells of the substantia nigra is assumed as the direct cause of
PD neurodegeneration and apoptosis has also been proposed to take part in this process (Anglade et al., 1997). SH-SY5Y cells, a sub line of human neuroblastoma cells (Xing et al., 2005), own some comparable characters with dopaminergic cells (Song et al., 2012) and are considered as a suitable cellular model of PD. The 6-OHDA, as a hydroxylated analogue of dopamine, is one of the common agents used to produce PD-like neural cell degeneration both in vivo and in vitro (Blum et al., 2001). In the

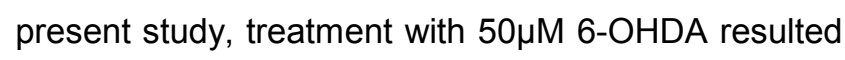
in mitochondrial activity alteration, as verified by MTT assay. The 6-OHDA, move in the cells through dopaminetransporter (Ljungdahl et al., 1971) and generates intracellular free radicals which triggers the activation of cell death pathways (Hwang, 2013). Similarly, it was suggested that the impairment of 
mitochondrial function and the resultant oxidative stress play roles in PD pathogenesis ( $\mathrm{Gu}$ et al., 1998). When SH-SY5Y cells were treated with nobiletin, it reversed 6-OHDA effect on cell viability at doses equal or higher than $50 \mu \mathrm{M}$. This result might be due to the antioxidant properties of nobiletin since evidence indicated that nobiletin exerts antioxidant effects both in vivo and in vitro (Zhang et al., 2016; Liu and $\mathrm{Wu}, 2018)$. Consistent with the findings of the present study, in animal models of PD, nobiletin is found to exert some protective effects. In MPTP triggered mice $\mathrm{PD}$, nobiletin increases dopamine release in striatum and hippocampal CA1. It also restores the attenuated activity of $\mathrm{Ca}^{2+} /$ calmodulindependent protein kinase II (CaMKII) and cAMPregulated phosphoprotein-32 (DARPP-32), restores the decreased activity of tyrosine hydroxylase (TH) and rescues MPTP-induced cognitive and motor dysfunctions (Yabuki et al., 2014). In the same way, in $\mathrm{MPP}^{+}$-triggered rat $\mathrm{PD}$, nobiletin not only protected dopaminergic neurons of substantia nigra, but also inhibits microglial activation and restores the expression of neurotrophic factor derived from the glial cells (Jeong et al., 2015).

Several studies identified the role of the mitochondrial-caspase cascade following 6-OHDA exposure, which triggers the activation of the main effector caspases-3 (Woodgate et al., 1999; Amiri et al., 2016). In agreement, the cleavage of caspase-3 was detected to be considerably increased in 6OHDA treated cells in the present study. Likewise, human postmortem studies suggested that, dopaminergic neurons die through apoptosis in PD (Anglade et al., 1997; Kingsbury et al., 1998) and the increase of caspase-3 immunoreactivity were shown in those neurons (Tatton, 2000). A number of investigations have shown the anti-apoptotic effect of nobiletin as a mechanism for its protective effect. For instance, nobiletin inhibited the apoptotic process in ischemic/reperfusion-exposed Kupffer cells after liver transplantation (Wu et al., 2017). Additionally, in pressure overload-induced myocardial damage (Zhang et al., 2017; Mao et al., 2019) and injured PC12 cells (Li et al., 2018), nobiletin reduced apoptosis. Based on previous investigations, in the present study, we hypothesized that nobiletin might exert anti-apoptotic effect in 6-OHDA exposed SHSY5Y cells. Accordingly, our study showed that nobiletin reversed caspase-3 cleavage indicating its anti-apoptotic effect. A recent study suggested the involvement of the phosphoinositide 3-kinase (PI3K)/protein kinase B (Akt) pathway in antiapoptotic effect of nobiletin (Mao et al., 2019). Activated Akt might exert an anti-apoptotic effect via the regulation of $\mathrm{Bax}$ and $\mathrm{Bcl}-2$ which control caspase-3 activation (Salakou et al., 2007). Although $\mathrm{Bcl}-2$ is anti-apoptotic, Bax is regarded as a proapoptotic factor and their relative expression determines the cell viability (Howard et al., 2002). Akt was shown to phosphorylate Bad at Ser136 which inactivates its activity and helps to maintain Bcl-2 function (Datta et al., 1997).

\section{Conclusion}

In conclusion, the present study showed that nobiletin protects against the lethal effect of 6-OHDA and subsequent apoptosis in a cellular model of PD. To our knowledge this is the first study assessing the effect of nobiletin on human neuroblastoma cells as an in vitro model of PD. Since recently nobiletin was suggested to protect against PD an animal models (Yabuki et al., 2014; Jeong et al., 2015), these in vitro findings are worthy in elucidating the mechanism of the protective effects of this flavonoid in PD.

\section{Acknowledgments}

This work was supported by the grants Number 9301-55-8285 and 93-01-55-8292 from Shiraz University of Medical Sciences, Shiraz, Iran.

\section{Conflict of interest}

The authors declare that they have no conflict of interests.

\section{References}

Amiri E, Ghasemi R, Moosavi M. Agmatine protects against 6-ohda-induced apoptosis, and erk and akt/gsk disruption in sh-sy5y cells. Cell Mol Neurobiol 2016; 36: 829-838. DOI: 10.1007/s10571-015-0266-7.

Blum D, Torch S, Lambeng N, Nissou M, Benabid AL, Sadoul R, et al. Molecular pathways involved in the neurotoxicity of 6-ohda, dopamine and mptp: Contribution to the apoptotic theory in parkinson's disease. Prog Neurobiol 2001; 65: 135-72. DOI: 10.1016/s0301-0082(01)00003-x.

Braidy N, Behzad S, Habtemariam S, Ahmed T, Daglia M, Nabavi SM, et al. Neuroprotective effects of citrus fruitderived flavonoids, nobiletin and tangeretin in alzheimer's and parkinson's disease. CNS Neurol Disord Drug Targets 2017; 16: 387-397. DOI: 
$10.2174 / 1871527316666170328113309$.

Chaudhry ZL, Ahmed BY. Caspase-2 and caspase-8 trigger caspase-3 activation following 6-ohda-induced stress in human dopaminergic neurons differentiated from renvm stem cells. Neurol Res 2013; 35: 435-40. DOI: 10.1179/1743132812y.0000000135.

Cohen GM. Caspases: The executioners of apoptosis. Biochem J 1997; 326 ( Pt 1): 1-16. DOI: 10.1042/ bj3260001.

Cui Y, Wu J, Jung SC, Park DB, Maeng YH, Hong JY, et al. Anti-neuroinflammatory activity of nobiletin on suppression of microglial activation. Biol Pharm Bull 2010; 33: 1814-21. DOI: 10.1248/bpb.33.1814.

Datta SR, Dudek H, Tao X, Masters S, Fu H, Gotoh Y, et al. Akt phosphorylation of bad couples survival signals to the cell-intrinsic death machinery. Cell 1997; 91: 231241. DOI: 10.1016/s0092-8674(00)80405-5.

Dodel RC, Du Y, Bales KR, Ling Z, Carvey PM, Paul SM. Caspase-3-like proteases and 6-hydroxydopamine induced neuronal cell death. Brain Res Mol Brain Res 1999; 64: 141-8. DOI: 10.1016/s0169-328x(98)00318-0

Dorszewska J, Prendecki M, Lianeri M, Kozubski W. Molecular effects of I-dopa therapy in parkinson's disease. Curr Genomics 2014; 15: 11-7. DOI: 10.2174/1389202914666131210213042.

Ferger B, Rose S, Jenner A, Halliwell B, Jenner P. 6hydroxydopamine increases hydroxyl free radical production and DNA damage in rat striatum. NeuroReport 2001; 12: 1155-1159.

Forno LS. Neuropathology of parkinson's disease. J Neuropathol Exp Neurol 1996; 55: 259-72.

Gu M, Cooper JM, Taanman JW, Schapira AH. Mitochondrial DNA transmission of the mitochondrial defect in parkinson's disease. Ann Neurol 1998; 44: 177-86. DOI: 10.1002/ana.410440207.

Hartmann A, Hunot S, Michel PP, Muriel MP, Vyas S, Faucheux BA, et al. Caspase-3: a vulnerability factor and final effector in apoptotic death of dopaminergic neurons in parkinson's disease. Proc Natl Acad Sci U S A 2000; 97: 2875-80. DOI: 10.1073/pnas.040556597.

He Y, Lee T, Leong SK. 6-hydroxydopamine induced apoptosis of dopaminergic cells in the rat substantia nigra. Brain Res 2000; 858: 163-166. DOI: 10.1016/s0006-8993(99)02459-2.

Howard S, Bottino C, Brooke S, Cheng E, Giffard RG, Sapolsky R. Neuroprotective effects of bcl-2 overexpression in hippocampal cultures: interactions with pathways of oxidative damage. J Neurochem 2002; 83: 914-23. DOI: 10.1046/j.1471-4159.2002.01198.x.

Huang H, Li L, Shi W, Liu H, Yang J, Yuan X, et al. The multifunctional effects of nobiletin and its metabolites in vivo and in vitro. Evid-Based Complementary Altern Med 2016; 2016: 2918796-2918796. DOI: 10.1155/ 2016/2918796.

Hwang $O$. Role of oxidative stress in parkinson's disease. Exp Neurobiol 2013; 22: 11-7. DOI: 10.5607/en. 2013.22.1.11

Ikeda Y, Tsuji S, Satoh A, Ishikura M, Shirasawa T, Shimizu T. Protective effects of astaxanthin on 6- hydroxydopamine-induced apoptosis in human neuroblastoma sh-sy5y cells. J Neurochem 2008; 107: 1730-1740. DOI: 10.1111/j.1471-4159.2008.05743.x.

Jeong KH, Jeon MT, Kim HD, Jung UJ, Jang MC, Chu JW, et al. Nobiletin protects dopaminergic neurons in the 1methyl-4-phenylpyridinium-treated rat model of parkinson's disease. J Med Food 2015; 18: 409-14. DOI: 10.1089/jmf.2014.3241.

Khan S, Ahmad K, Alshammari EM, Adnan M, Baig MH, Lohani M, et al. Implication of caspase-3 as a common therapeutic target for multineurodegenerative disorders and its inhibition using nonpeptidyl natural compounds. BioMed Res Int 2015; 2015: 379817. DOI: 10.1155/2015/379817.

Kingsbury AE, Mardsen CD, Foster OJ. DNA fragmentation in human substantia nigra: apoptosis or perimortem effect? Mov Disord 1998; 13: 877-84. DOI: 10.1002/ mds.870130604.

Lees AJ, Hardy J, Revesz T. Parkinson's disease. Lancet 2009; 373: 2055-66. DOI: 10.1016/S0140-6736(09) 60492-X.

Li ZR, Yang L, Zhen J, Zhao Y, Lu ZN. Nobiletin protects pc12 cells from ers-induced apoptosis in ogd/r injury via activation of the pi3k/akt pathway. Exp Ther Med 2018; 16: 1470-1476. DOI: 10.3892/etm.2018.6330.

Liu L, Wu XW. Nobiletin protects human retinal pigment epithelial cells from hydrogen peroxide-induced oxidative damage. J Biochem Mol Toxicol 2018; 32: e22052. DOI: 10.1002/jbt.22052.

Ljungdahl A, Hokfelt $T$, Jonsson G, Sachs C. Autoradiographic demonstration of uptake and accumulation of 3h-6-hydroxydopamine in adrenergic nerves. Experientia 1971; 27: 297-9. DOI: 10.1007/ bf02138157.

Lotharius J, Dugan LL, O'Malley KL. Distinct mechanisms underlie neurotoxin-mediated cell death in cultured dopaminergic neurons. J Neurosci 1999; 19: 1284-93. doi: 10.1523/JNEUROSCI.19-04-01284.1999.

Lowry $\mathrm{OH}$, Rosebrough NJ, Farr AL, Randall RJ. Protein measurement with the folin phenol reagent. J Biol Chem 1951; 193: 265-75.

Mao Q, Liang X, Wu Y, Lu Y. Nobiletin protects against myocardial injury and myocardial apoptosis following coronary microembolization via activating pi3k/akt pathway in rats. Naunyn-Schmiedeberg Arch of Pharmacol 2019. DOI: 10.1007/s00210-019-01661-y.

Moosavi M, Farrokhi MR, Tafreshi N. The effect of curcumin against 6-hydroxydopamine induced cell death and akt/gsk disruption in human neuroblastoma cells. Physiol Pharmacol 2018; 22: 163-171.

Nemoto K, Ikeda A, Yoshida C, Kimura J, Mori J, Fujiwara $\mathrm{H}$, et al. Characteristics of nobiletin-mediated alteration of gene expression in cultured cell lines. Biochem Biophys Res Commun 2013; 431: 530-4. DOI: 10.1016/j.bbrc.2013.01.024.

Onozuka H, Nakajima A, Matsuzaki K, Shin RW, Ogino K, Saigusa D, et al. Nobiletin, a citrus flavonoid, improves memory impairment and abeta pathology in a transgenic mouse model of alzheimer's disease. J 
Pharmacol Exp Ther 2008; 326: 739-44. DOI: 10.1124/jpet.108.140293.

Perier C, Bove J, Vila M. Mitochondria and programmed cell death in parkinson's disease: apoptosis and beyond. Antioxid Redox Signal 2012; 16: 883-95. DOI: 10.1089/ars.2011.4074

Salakou S, Kardamakis D, Tsamandas AC, Zolota V, Apostolakis E, Tzelepi V, et al. Increased bax/bcl-2 ratio up-regulates caspase- 3 and increases apoptosis in the thymus of patients with myasthenia gravis. In Vivo 2007; 21: 123-32. no DOI.

Sasaki K, Yoshizaki F. Nobiletin as a tyrosinase inhibitor from the peel of citrus fruit. Biol Pharm Bull 2002; 25: 806-8. DOI: 10.1248/bpb.25.806.

Song JX, Shaw PC, Wong NS, Sze CW, Yao XS, Tang $\mathrm{CW}$, et al. Chrysotoxine, a novel bibenzyl compound selectively antagonizes $\mathrm{mpp}(+)$, but not rotenone, neurotoxicity in dopaminergic sh-sy5y cells. Neurosci Lett 2012; 521: 76-81. DOI: 10.1016/j.neulet. 2012.05.063.

Sookhaklari R, Geramizadeh B, Abkar M, Moosavi M. The neuroprotective effect of bsa-based nanocurcumin against 6-ohda-induced cell death in sh-sy5y cells. Avicenna J Phytomed 2019; 9: 92-100. no DOI.

Tatton NA. Increased caspase 3 and bax immunoreactivity accompany nuclear gapdh translocation and neuronal apoptosis in parkinson's disease. Exp neurol 2000; 166: 29-43. DOI: 10.1006/exnr.2000.7489.

Woodgate A, MacGibbon G, Walton M, Dragunow M. The toxicity of 6-hydroxydopamine on pc12 and p19 cells. Molecular Brain Research 1999; 69: 84-92. DOI: 10.1016/s0169-328x(99)00103-5.

Wu Y, Zhang W, Li M, Cao D, Yang X, Gong J. Nobiletin ameliorates ischemia-reperfusion injury by suppressing the function of kupffer cells after liver transplantation in rats. Biomed Pharmacother 2017; 89: 732-741. DOI: 10.1016/j.biopha.2017.02.087.

Xie HR, Hu LS, Li GY. Sh-sy5y human neuroblastoma cell line: In vitro cell model of dopaminergic neurons in parkinson's disease. Chin Med J (Engl) 2010; 123: 1086-92. DOI: 10.3760/cma.j.issn.0366-6999.2010. 08.021.

Xing C, Peng Y, Chang R, Yin Y, Xie Z. Effects of insulinlike growth factor-1 on okadaic acid-induced apoptosis in sh-sy5y cells. Cell Biol Int 2005; 29: 803-8. DOI: 10.1016/j.cellbi.2005.04.012.

Yabuki Y, Ohizumi Y, Yokosuka A, Mimaki Y, Fukunaga K. Nobiletin treatment improves motor and cognitive deficits seen in mptp-induced parkinson model mice. Neuroscience 2014; 259: 126-41. DOI: 10.1016/j.neuroscience.2013.11.051.

Yamada M, Kida K, Amutuhaire W, Ichinose F, Kaneki M. Gene disruption of caspase-3 prevents mptp-induced parkinson's disease in mice. Biochem Biophys Res Commun 2010; 402: 312-8. DOI: 10.1016/j.bbrc. 2010.10.023.

Zhang L, Zhang X, Zhang C, Bai X, Zhang J, Zhao X, et al. Nobiletin promotes antioxidant and anti-inflammatory responses and elicits protection against ischemic stroke in vivo. Brain Res 2016; 1636: 130-41. DOI: 10.1016/j.brainres.2016.02.013.

Zhang N, Wei W-Y, Yang Z, Che Y, Jin Y-G, Liao H-H, et al. Nobiletin, a polymethoxy flavonoid, protects against cardiac hypertrophy induced by pressure-overload via inhibition of napdh oxidases and endoplasmic reticulum stress. Cell Physiol Biochem 2017; 42: 1313-1325. DOI: 10.1159/000478960. 